\title{
Responsive Turns in L2 Discussion Tasks: A Conversation Analysis Perspective
}

\author{
Huong Quynh Tran \\ Hanoi National University of Education, Hanoi, Vietnam
}

\begin{abstract}
With an emphasis on the significant roles of contextualization and interaction in language learning, there has been an increasing interest in micro-analysis of language-in-use in classroom contexts. However, there have been few studies of language-in-use in learner-learner interaction in EFL contexts, especially with the focus on responsive turns, a component to achieve topic extension in interactional competence. This paper, thus, explores the responsive turns that the students in a Vietnamese context constructed in discussion tasks from a conversational analysis perspective. The data set was video-recorded discussion tasks by twelve students of pre-intermediate level of English in two English classrooms at a pedagogical university in Vietnam. The findings show four features of turn construction in the students' exchanges. The discussion contributes to the body of knowledge on student talk in classroom interaction and provides some implications for responsive turn practice in EFL contexts.
\end{abstract}

Despite the increasing need to learn authentic oral skills in EFL contexts, including those in ASEAN, there is a gap between student practice in language speaking tasks and communicative interactions outside the classroom, caused, at least in part, by failure to extend the topic (Koester, 2010). Topic extension, the way speakers develop their topic through interrelation or abruption from the information in prior turns (Galaczi, 2014; Wong \& Waring, 2010), is one of the fundamentals in interactional competence by which students create coherence in discussion (Gan, Davison, \& Hamp-Lyons, 2008; Young, 2008). However, little research has been directed to topic extension and the ways in which EFL students progressively co-construct and develop responsive turns to achieve this continuity during classroom interaction tasks.

With the introduction of communicative language teaching, the use of paired or group-work activities, including discussion tasks, has been promoted to elicit students' spoken language-inuse and their communicative interaction in the target language. Classroom discussion tasks with guided questions have been used to facilitate opportunities for collaboration (Harmer, 2007), a crucial feature in language acquisition (Kasper \& Kim, 2015). As teacher-fronted classrooms are being gradually replaced by group work in the ASEAN region, analytic research focus needs to move to interaction among learners. However, microanalysis in students' talk during their interaction to accomplish teacher-assigned discussion tasks has been largely unaddressed.

For the above reasons, this study seeks the answer to the following research question: How do the students construct their responsive turns to extend the topic in L2 discussion tasks?

Language Education in Asia, 2016, 72), 100-113. https://doi.org/10.5746/LEiA/16/V7//2/A04/Tran 
This study provides an insight into how EFL students in a specific English learning context design their responsive turns in discussion tasks from a conversation analysis (CA) perspective. It aims to contribute to the body of knowledge on student talk in in-class interactions in the ASEAN region and to that on English language teaching pedagogies for developing interactional competence in general and classroom interactional competence in particular. Four emerging themes in responsive turns are analysed: the repetition of lexical and structural resources between a task-guided question turn and its responsive turn; the dominant pattern of opinionreasons in responsive turns; gaze disengagement for independent word-search; and wordsearch through thinking aloud in the L1 - Vietnamese.

\section{Discussion Tasks}

\section{Literature Review}

As a task designed for language practice in in-class speaking lessons, L2 discussion is promoted for two main purposes. First, it helps elicit students' spoken language-in-use and communicative interaction in the target language. A discussion task is considered a vehicle for achieving language outcomes because it establishes a context for students to use the target language (Bygate, Skehan, \& Swain, 2001; Ellis, 2003; Kim, 2015). Second, through this medium for learning and practising the target language in class, learning opportunities occur during students' interaction to complete the task (Gardner, 2013). In this study, a teacherassigned L2 discussion task in EFL speaking lessons asked the students to talk about a topic or an issue. It was guided by a discursive question or a series of questions, which can be called task-guided questions, to help students elaborate on the discussion. In a discussion task, the students usually work in pairs or groups without interference from the teachers.

The majority of studies on speaking tasks, including discussion tasks in Asia, have limited their focus on the procedure to implement a task in a specific context to promote students' communication abilities (e.g., Doan, 2011; Hamciuc, 2014; Harms \& Myers, 2013; Thompson \& Millington, 2012). They tended to focus on techniques to enhance the students' confidence (e.g., Harms \& Myers, 2013, with a round-table technique) and to increase the students' participation in a task (e.g., Aubrey, 2011; Hendryx, 2012; Le, 2007). Some studies showed that factors such as group setting or topic relevancy probably affect the students' interaction in and contribution to the tasks in class (Aubrey, 2011; Le, 2007). These studies tended to use quantitative methods or case studies with interviews and questionnaires to explore the issues. Some studies, such as Hauser $(2009,2010)$ and Le (2007), have started to focus on the students' performance by analysing their exchanges during the task. The focus has moved from the quantitative frequency of a linguistic feature in the exchanges (Le, 2007) to the analysis of turntaking organization and mutual interaction in and through students' language in-use within classroom interaction. In contribution to this emerging trend, this study explores students' responsive turns in discussion tasks from a CA perspective.

\section{Responsive Turns in Topic Extension}

From a CA perspective, talk-in-interaction is premised on an understanding of the organization of social order and turn-taking in natural spoken interaction (Seedhouse, 2004). Speakers present the contiguity of talk and lead to the interplay among participants in the sequence of successive turns (Drew, 2013). By responding to the prior turn, speakers extend the topic, which is an important practice in language education because it demonstrates the highest connection between the recipient and the speaker (Waring, 2002). Waring argued that extending the topic, as a feature of "substantive recipiency" (p. 464), can characterise the subsequent action. As Waring affirmed, extending "involves stretching out a prior explication or assertion ... to ensure the full development of such explication or assertion" (p. 464). 
Further, Nguyen (2011) stressed that speakers need to negotiate on an ongoing topic to participate in a conversation through initiating topics or contributing to the current talk. By doing so, speakers contribute to and extend the ongoing topic. Extending the topic, therefore, develops understanding of a discussion.

In discussion tasks, students construct their responsive turns to provide answers to either the task-guided questions or the follow-up questions emerging in the exchange. Through the coconstruction of meaning in responsive turns, students experience and acquire the target language. Responsive turns in L2 discussion tasks, normally the answers to the task-guided questions, contribute to the co-construction of topic extension.

\section{Methodology}

The study is part of a larger research project in which the focus is on topic extension in discussion tasks in an EFL context. This study is grounded in both the research findings and methodology of CA to explore the students' responsive turns in discussion tasks in a pedagogical university in Vietnam. The participants were second-year pre-service teachers of English, between 18 and 20 years of age, whose English was at the pre-intermediate level. As English teacher trainees in an EFL context, they were required to study the knowledge domains for English language proficiency development, including the four skills of English.

The set of data was the video-recordings of L2 discussion practices among 12 participants in 10 three-hour English lessons. The recorded L2 discussions arose in the naturally occurring sequence of English lessons without any manipulation or controlled guidance by the researcher. Whenever there was a discussion task in class, the participants followed the instructions and worked with each other in pairs or in groups. As a CA-grounded study, transcribing data strictly followed the CA transcription conventions (see Appendix) to consistently capture and present the data in highly detailed transcripts (Hepburn \& Bolden, 2013). The analysis was data-driven without any prior theoretical assumptions. The emerging themes were then referred back to the literature for discussion.

\section{Findings}

\section{Repetition of Vocabulary and Structure Between a Guided Question and Its Response}

Extract 1

Guided questions:

Where is the last place you visited on the sightseeing trip? Did you enjoy it?

What is the best place you have visited?

What is the best way to look around a city? 


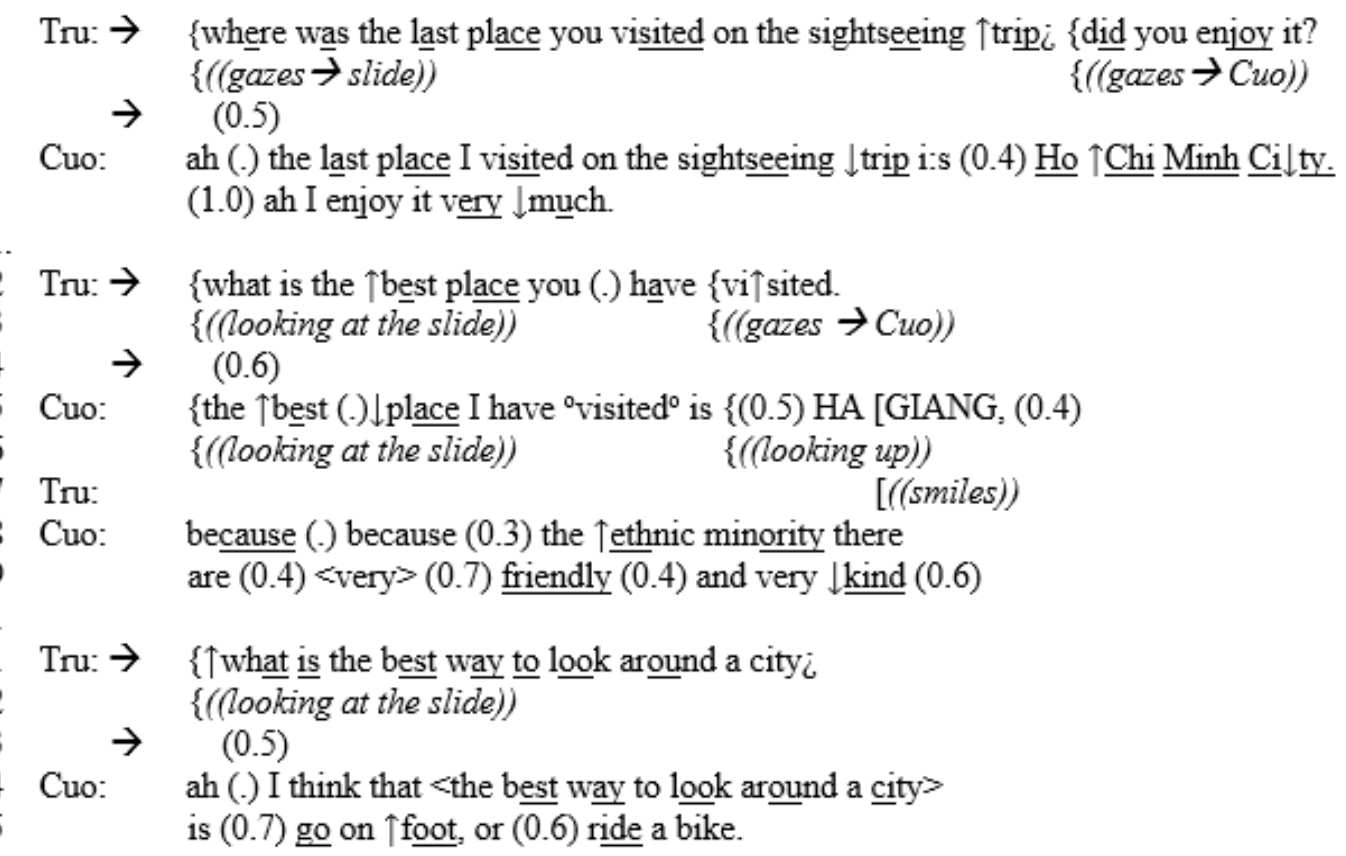

In this extract, the students use the guided questions for the task to create a series of questionanswer pairs, called adjacency pairs, to extend the topic. In the first pair (Lines 1-5), Cuong uses partial repetition of the vocabulary and grammatical structure of the guided question (Lines $4,5)$ with a turn preface ah to construct the responsive turn. Although it is a shared guided question, there is still a gap of 0.5 seconds (Line 3 ) between the questioning turn and the responding turn. In the responding turn, there is a small gap ( 0.4 seconds) between the repetition part and the answer. The students seem to initiate the response by adopting the lexical and structural repetition of the question to create the connection between the current response and the question and to have time to think of a response. Gaps between the question and answer, and within the responsive turn, show that the students need time to either think of an idea or retrieve vocabulary.

The pattern is repeated in the second question-answer pair (Lines 12-15). Cuong starts his response by repeating part of the question (Line 15) before nominating the best place. There is also a pause between the repetition part and the answer. Cuong tends to give the answers in full grammatical sentences. In the next part of his turn, Cuong includes an explanation to justify his selection, which is initiated by the word because. This pattern can also be observed in the last pair part of the adjacency pair (Lines 31-35); the repetition of vocabulary is followed by a 0.7-second gap before Cuong's choice as the main informing answer to the question.

Such lexical or structural repetition between a guided question and its response is illustrated in Figure 1.

- Turn 1: Task-guided question

- gap

- Turn 2: Responsive turn:

repetition of the vocabulary and structure in the guided question pause answer or information requested by the question

Figure 1. Sequence of a question and its responsive turn. 
Although full sentences in responsive turns are observed frequently in the data, in the extension part of the discussion with follow-up questions, ellipsis, the omission of words in use, occurs in many sequences.

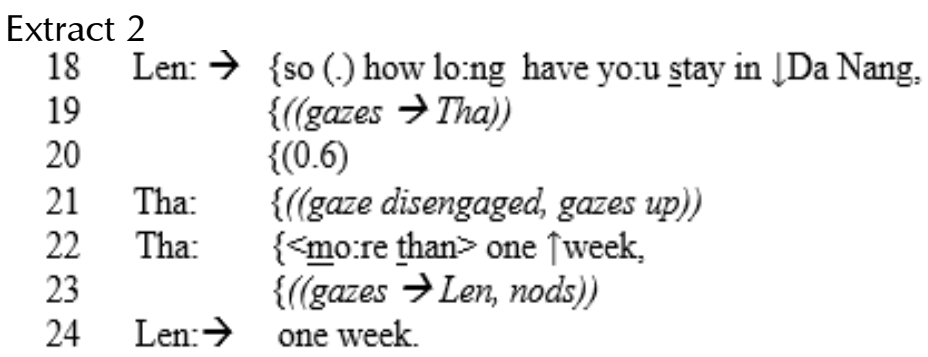

In Line 18, the response turn to the follow-up question is not constructed with repetition to create the connection with the prior turn. Instead, Thao focuses on meaning (see Sheen, 2002) to construct the turn (Line 22) by using ellipsis, which is repeated by Len in the third turn (Line 24 ) as a receipt move. When students in the current corpus extended the topic, they were more likely to focus on meaning and the exchange of information. As a result, their language contained more features of natural or authentic interaction.

\section{The Dominant Pattern of Opinion-Reasons in Responsive Turns}

The opinion-reason pattern with because in the responsive turns appears to dominate in the construction of responsive turns. The students formulate their extension of a turn with a reason, as illustrated in Extract 3.

Extract 3

Guided questions:

Where was the last place you visited on your sightseeing trip?

Did you enjoy it?

Who did you go with?

What did you do?

20 Chi: so: (0.3) who did you $\uparrow$ go with.

21 Tam: ah, I go with $\{()<.\mathrm{I}$ went to $>$ I went there with my family, and

$22 \quad$ ((looks up, nods $)$ \}

23 my friends, some of my friends,

24 Chi: \$wow\$

25 Tam: $\rightarrow$ because, (0.3) there are (.) there were some friends of mine there,

26 so the weather, $\{(0.2)$ the bad weather is not a problem.

27

28 Chi: $\quad\left\{\$^{\circ}\right.$ see $\$$

29 Tam: $\rightarrow$ I: (0.2) spent (0.2) my holiday in the (0.4) both in a hotel, and the beach (0.8)

$30 \rightarrow$ but, (0.7) because of the bad weather (0.4) SIS (0.6) didn't have

31 a (0.4) more chance to (.) go to the beach, (0.2)

In this extract, Chi is the questioner and Tam is an information giver when they talk about their last sightseeing trip. While constructing turns, Tam repeats the structure and vocabulary from the guided question as a means to create the link between her answer and the question before she extends the turn into a multi-unit one with reasons using because (Line 25). She continues to extend her talk to describe activities without prompting from Chi. However, Tam gives the 
answer to the next guided question as she also knows what the guided questions are. She again extends her turn with because (Line 30).

\section{Gaze Disengagement for Independent Word-Search}

When the students pause to conduct a word search, they generally look away. Their word searches can be accompanied by hand gestures, and in most cases, the students attempt to provide their own solution without seeking assistance from their peers. Moreover, their peers in these situations do not offer help even when there are long pauses during the word searches, which may indicate some trouble, as in Extract 4.

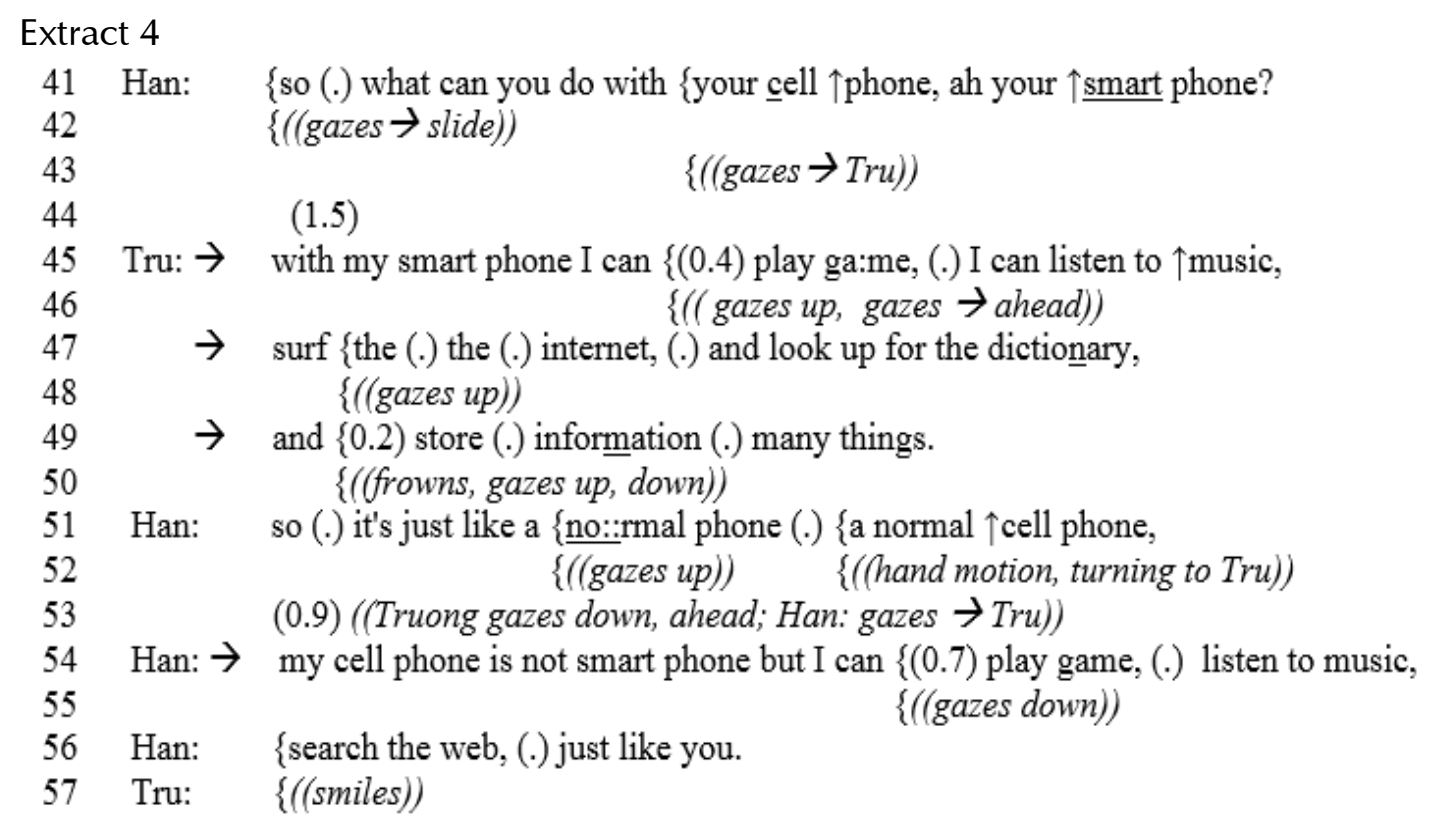

Both Han and Truong try to find words or phrases to express their ideas independently although their gestures and gaze disengagement suggest some effort in selecting the target vocabulary. The pause in Line 45 and the repetition of the in Line 47 show that Truong needs time for his word search. Such behaviours are accompanied by gaze withdrawal, which is directed up or down. In Line 45, Truong talks about the activities he can do with his phone. He initiates the talk with "with my smart phone I can" and the repetition of vocabulary and structure from the guided question, followed by a 0.4-second pause. During this pause, he directs his eyes up and ahead. On retrieving the word, he continues his turn with a list (Line 45) and then again conducts a word search in Line 47 when he repeats the word the with pauses while thinking. Similarly, Han's word selection occurs with a pause ( 0.7 seconds) and gaze discontinuation in Line 54.

\section{Word Search Through Thinking Aloud in Vietnamese}

Another feature of word search, the use of Vietnamese, the first language, as assistance to recall the needed lexical item, is found in the data. By self-talking in Vietnamese, the students immediately retrieve the word. 


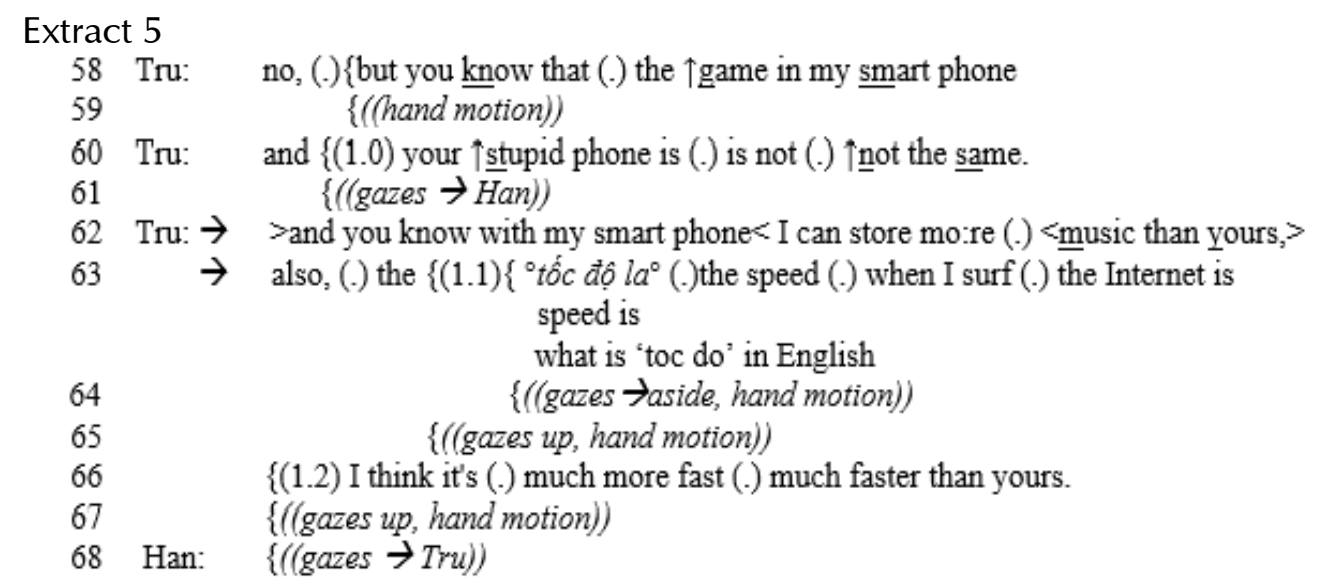

In Line 63, Truong is searching for the word speed to express his argument but cannot immediately retrieve this word. After a long pause (1.1 seconds), Truong switches to Vietnamese, uttered softly to himself, to search for the word and then translates it. This action might be explained by the ways in which students learn L2 vocabulary-usually by translating a new word into the L1 or memorizing a lexical item by finding an equivalent phrase in the L1. At the same time, Truong directs his gaze up while beating his hands, indicating that he is trying to recall the word. Again, as above, by disengaging his gaze from Han's, Truong shows that he wants to manage the turn by himself. In Line 65, Truong also needs a long pause with gaze disengagement for his next word search.

\section{Discussion}

Repetition has been shown to be used for many functions. First, in L2 language users, it can be seen as an indicator of hesitancy through disfluency (Scollon \& Scollon, 2001). This is usually observed in the action of word searches (Lerner, 1995). Second, repetition of the preceding turn, either full or part, involves a repair procedure (Filipi, 2015; Hall, 2007) or an assessment (Hellermann, 2004), which occurs mainly in the third position in teacher-student interaction, the teacher's response to the student's responsive turn. Third, repetition marks receipt of information (Hellermann, 2007; Hosoda \& Aline, 2013). Fourth, repetition can be used to pursue responses owing to the inadequate response in the prior turn or when an answer is not forthcoming (Filipi, 2015; Hosoda \& Aline, 2013).

The analyses in this study, however, show that the students tend to partially repeat the vocabulary and sometimes the structure of the guided question to initiate the responsive second turn in the question-answer pair. Repetition, along with responsive actions and ellipsis, is one strategy to create cohesion when it displays the connection between the current turn and the preceding turn (Drew, 2013). Likewise, the students' repetition may create the lexical connection between two pair parts of an adjacency pair. Repetition, as Drew stated, tends to occur at the beginning of a turn to create this lexical connection. This analysis aligns with Lerner's (1995) argument that the lexical repetition between a $w h$-type question and its response is type matched. The speakers may use part of the question to design the beginning of the subsequent responsive turn.

The students also tend to construct the response to a guided question in a full sentence, creating a connection to the question as analysed above. It also may reflect the students' understanding of the expected response. Roebuck and Wagner (2004) suggested that students should be trained to use repetition, including repeating part of the teacher's questions while constructing 
the responsive turn. They argued that it may be an effective tool for students with low levels of English proficiency. However, it sometimes creates redundancy as speakers in natural conversation seem to focus on responsive information rather than the repetition part leading to the response. Therefore, in many cases, proficient speakers use ellipsis (Halliday \& Hassan, 1976) to focus on responsive information. In language practice, it also balances the focus on form and the focus on meaning (Sheen, 2002) to help the students control their turn construction.

In Extract 2, the responsive turn to the follow-up question is an ellipsis. Although the turn (Line 22) does not repeat part of the question, it focuses on responsive information. The ellipsis feature tends to be common in natural conversation, as seen in many extracts in the literature (e.g., Stivers, 2010). When the students extend the topic with follow-up questions, they focus on the meaning and the exchange of information. As a result, their language contains more features of natural or authentic interaction. To some extent, such extension of the topic enables the students to focus on meaning, creating meaningful contexts for students to practise and experience the target language.

The occurrence of ellipsis in the follow-up sequence and the absence of this feature in the taskguided question sequence suggest implications for language development in that students should be exposed more to features of natural or authentic interaction. Students should also be encouraged to extend the topic with follow-up questions to experience the diverse features of more communicative interaction in their use of English. This becomes significant in EFL educational contexts where the target language exposure outside classroom is limited.

The gaps between questioning turns and responsive turns in these extracts are quite long (Extract 1, Lines 3 and 6; Extract 2, Line 20; Extract 4, Line 44). Although in the literature, conversations among L2 language learners at a lower level of English proficiency tend to have no-overlap or no-gap turn transitions as the students are able to take turns at the precise timing (Hauser, 2009), long gaps between turns and pauses (as illustrated in Figure 1) within responsive turns seem to indicate either poor interactional competence or lack of engagement in the interaction.

The dominating pattern of opinion-reasons found in students' responsive turns, as illustrated in Extract 3, echo the findings in Hauser's $(2009,2010)$ studies when students formulated a turn with because to add one or two reasons for turn extensions. The current set of data shows the dominance of the opinion-reason pattern as a vehicle for students to extend their turn into a multi-unit turn. However, adding reasons is not the only way of extending responsive turns. Rather, they can be constructed with a wide range of patterns such as giving an explanation, giving opinions, describing, comparing, and contrasting. Therefore, students should experience different ways to extend turns and topics to fully experience the target language in discussion tasks. They need detailed guidelines and scaffolding from the teacher.

A possible explanation for this way of turn construction is an adoption or influence of the teacher's actions in their instruction or conversations for eliciting ideas with students.

Hellermann's (2007) findings also show that students tend to adopt their teacher's talk in class for later use in other group-work or pair-work conversations. Therefore, besides encouraging students to extend turns more flexibly with other patterns, teachers also need to vary the language they use in class to elicit students' responses so that students can imitate the teacher's ways of extending turns in their tasks. 
The analysis shows that in their practise of English, the students tend to construct their responsive turns independently while they attempt to express an idea in the target language, even when they need to pause for a word search. In Extract 4, by withdrawing gaze engagement during the word search time, the students' action is aligned with the findings for self-initiated / self-completed word searches in the literature (see, e.g., Kasper \& Wagner, 2011). In Extract 5, the use of Vietnamese as a language switch for word search acts as meta-talk to help the student link his thought with the English word (see Ellis, 2012). As Storch and Wigglesworth (2003) stated, discussing vocabulary and meaning is one of four main functions of L1 use in students' interactions. Therefore, when they need to retrieve a word or a phrase, a language switch to L1 (Vietnamese) tends to be helpful. This also reflects the habit of learning a lexical item with its meaning in L1 in the Vietnamese EFL learning context.

However, the repeating occurrence of the word search, which usually occurs in the extending part of the turn, normally from the second turn unit forward, may indicate the lack of vocabulary for the topic of discussion. The students seem not to retrieve the vocabulary as fast as they need to speak fluently. When they need to do a word search, they disengage to independently think of a word. Although it is good for constructing the turn by themselves, the students also need to learn how to co-construct the turns. In Extracts 4 and 5, evidence of word searches is apparent, but the listeners in those turns do not offer help in such word-search actions. The focus in the task still seems to be within the frame of practice rather than communication. Students, hence, need teachers' support to develop their ability in coconstructing the meaning and responsive turns in discussion tasks.

By exploring the students' talk-in-interaction through microanalysis, the study revealed four features of responsive turns. The findings suggest that students' language-in-use in their interactional practice should be used more frequently to understand students' obstacles in speaking the target language. If students have chances to explore their interactional features by watching or listening to their performance, they will possibly have a positive reflection on their performance, resulting in the development of their L2 practice.

\section{Limitations of the Study}

The first limitation of the study relates to the participant selection. The participants' English level was estimated approximately, owing to the guidance in the development of English proficiency in the course; the participants were not officially tested to ensure that they were in the pre-intermediate level. The second issue relates to some extraneous variables that might affect the way the students extended the topics that were not under investigation. Possibly they include the lecturers' task instruction, the preparation tasks before the discussions and the grouping methods. This limitation also suggests the need for further studies of these interrelationships to topic extension from CA perspectives by analysing the practices in a series of tasks in a lesson.

\section{Conclusion}

This study is grounded in a CA perspective to explore features of responsive turns that students constructed in a Vietnamese EFL context. Through the microanalysis of the students' interaction at the pre-intermediate level of English, four emergent features of the students' responsive turns to the task-guided questions in discussion tasks are found. Firstly, it reveals the repetition of the lexical items, and sometimes of the grammatical structure between the responsive turn and its guided question. The interaction tended to align with the language practice purpose of a task, rather than with a communicative purpose. However, the repetition instances rarely occurred when the students extended the topic with follow-up questions. Rather, they focused more on 
meaning and information. The responsive turns in such sequences also contain more features of natural interaction such as the use of ellipsis. Secondly, the analysis has uncovered the domination of the opinion-reason pattern in responsive turns. It suggests the students' limitation in developing multi-unit turns when they constructed responsive turns. Thirdly, the study shows the repeating occurrence of word search in students' interaction, indicating the lack of active vocabulary for the topic of discussion. The students' disengagement of eye contact to independently retrieve the word and to continue their turn suggests the need for learning some interactional techniques to co-construct the meaning in discussion. Finally, the analysis explicates the meta-talk in Vietnamese helped the students search for a word or a phrase in the target language.

By making the features of responsive turns visible with microanalysis from a CA perspective, the findings suggest that teachers should raise students' awareness of their language-in-use by analysing their performance in detail. This can be done with clear guidance of interactional features and learning foci. It also suggests that teachers should vary the ways they elicit responses in interactions so students can adopt the language for later use. Further research could be conducted regarding the use of microanalysis in raising the students' awareness of interactional features as well as in reflecting their performance.

\section{Author Note}

Huong Quynh Tran, Faculty of English, Hanoi National University of Education, Hanoi, Vietnam.

Huong Quynh Tran received her PhD from the Faculty of Education, Monash University, Australia. She is an EFL lecturer at Hanoi National University of Education, Vietnam, with over 10 years of teaching experience. Her research interests include applying conversation analysis to EFL-learning issues, and innovative EFL pedagogy.

The paper presents part of the findings of the author's doctoral dissertation. The author would like to thank Dr. Anna Filipi and Dr. Miriam Faine for their comments on an earlier draft of this article.

Correspondence concerning this article should be addressed to Huong Quynh Tran, Faculty of English, Hanoi National University of Education, 136 Xuan Thuy, Cau Giay, Hanoi, Vietnam.

E-mail: quynhth@hnue.edu.vn 


\section{References}

Aubrey, S. (2011). Facilitating interaction in East Asian EFL classrooms: Increasing students' willingness to communicate. Language Education in Asia, 2(2), 237-245. https://doi.org/10.5746/LEiA/11/V2/I2/A06/Aubrey

Bygate, M., Skehan, P., \& Swain, M. (2001). Introduction. In M. Bygate, P. Skehan, \& M. Swain (Eds.), Researching pedagogic tasks: Second language learning, teaching and testing (pp. 1-20). New York, NY: Pearson Education.

Doan, L. C. (2011). Guidance for learners' improvement of speaking skills. Language Education in Asia, 2(1), 213-226. https://doi.org/10.5746/LEiA/11/V2/I2/A04/Doan

Drew, P. (2013). Turn design. In J. Sidnell \& T. Stivers (Eds.), The handbook of conversation analysis (pp. 131-149). Chichester, UK: Wiley-Blackwell. https://doi.org/10.1002/9781118325001.ch7

Ellis, R. (2003). Task based language learning and teaching. Oxford, UK: Oxford University Press.

Ellis, R. (2012). Language teaching research \& language pedagogy. Malden, MA: WileyBlackwell.

Filipi, A. (2015). The development of recipient design in bilingual child-parent interaction. Research on Language \& Social Interaction, 48(1), 100-119. https://doi.org/10.1080/08351813.2015.993858

Galaczi, E. D. (2014). Interactional competence across proficiency levels: How do learners manage interaction in paired speaking tests? Applied Linguistics, 35(5), 553-574. https://doi.org/10.1093/applin/amt017

Gan, Z., Davison, C., \& Hamp-Lyons, L. (2008). Topic negotiation in peer group oral assessment situations: A conversation analytic approach. Applied Linguistics, 30(3), 315-334. https://doi.org/10.1093/applin/amn035

Gardner, R. (2013). Conversation analysis in the classroom. In J. Sidnell \& T. Stivers (Eds.), The handbook of conversation analysis (pp. 593-611). Chichester, UK: Wiley-Blackwell.

Hall, J. K. (2007). Redressing the roles of correction and repair in research on second and foreign language learning. The Modern Language Journal, 91(4), 511-526. https://doi.org/10.1111/j.1540-4781.2007.00619.x

Halliday, M. A. K., \& Hassan, R. (1976). Cohesion in English. London, UK: Longman.

Hamciuc, M. (2014). Exchange classes: A strategy for enhancing student communicative competence and confidence. Language Education in Asia, 5(1), 142-150. https://doi.org/10.5746/LEiA/14/V5/I1/A11/Hamciuc

Harmer, J. (2007). The practice of English language teaching (4th ed.). Harlow, UK: Pearson Education.

Harms, E., \& Myers, C. (2013). Empowering students through speaking round tables. Language Education in Asia, 4(1), 39-59. https://doi.org/10.5746/LEiA/13/V4/I1/A4/Harms_Myers

Hauser, E. (2009). Turn-taking and primary speakership during a student discussion. In H. t. Nguyen \& G. Kasper (Eds.), Talk-in-interaction: Multilingual perspectives (pp. 215-244). University of Hawai'i at Manoa, National Foreign Language Resource Center.

Hauser, E. (2010). Designing an opinion for its (local) context. Human Studies, 33(4), 395-410. https://doi.org/10.1007/s10746-010-9167-4

Hellermann, J. (2004). The interactive work of prosody in the IRF exchange: Teacher repetition in feedback moves. Language in Society, 32, 79-104.

Hellermann, J. (2007). The development of practices for action in classroom dyadic interaction: Focus on task openings. The Modern Language Journal, 91(i), 83-96. https://doi.org/10.1111/j.1540-4781.2007.00503.x

Hendryx, J. D. (2012). Six strings of student groupings: applying Sunzi to the language classroom. Language Education in Asia, 3(2), 176-183. https://doi.org/10.5746/LEiA/12/V3/I2/A06/Hendryx 
Hepburn, A., \& Bolden, G. B. (2013). The conversation analytic approach to transcription. In J. Sidnell \& T. Stivers (Eds.), The handbook of conversation analysis (pp. 57-76.). Chichester, UK: Wiley-Blackwell.

Hosoda, Y., \& Aline, D. (2013). Two preferences in question-answer sequence in language classroom context. Classroom Discourse, 4(1), 63-88. https://doi.org/10.1080/19463014.2013.783497

Jefferson, G. (2004). Glossary of transcript symbols with an introduction. In G. H. Lerner (Ed.), Conversation analysis: Studies from the first generation (pp. 13-31). Amsterdam: John Benjamins.

Kasper, G., \& Kim, Y. (2015). Conversation-for-learning: institutional talk beyond the classroom. In N. Markee (Ed.), The handbook of classroom discourse and interaction (pp. 390-408). Oxford, UK: John Wiley \& Sons. https://doi.org/10.1002/9781118531242.ch23

Kasper, G., \& Wagner, J. (2011). A conversation-analytic approach to second language acquistion. In D. Atkinson (Ed.), Alternative approaches to second language acquisition (pp. 117-142). New York, NY: Routledge.

Kim, Y. (2015). The role of tasks as vehicles for language learning in classroom interaction. In N. Markee (Ed.), The handbook of classroom discourse and interaction (pp. 163-181). Oxford, UK: John Wiley \& Sons. https://doi.org/10.1002/9781118531242.ch10

Koester, A. (2010). Conversation analysis in the language classroom. In S. Hunston \& D. Oakey (Eds.), Introducing Applied Linguistics: Concepts and skills (pp. 35-47). London: Routledge.

Le, P. H. H. (2007). The more knowledgeable peer, target language use, and group participation. The Canadian Modern Language Review, 64(2), 329-350. https://doi.org/10.3138/cmlr.64.2.329

Lerner, G. H. (1995). Turn design and the organization of participation in instructional activities. Discourse Processes, 19(1), 111-131. https://doi.org/10.1080/01638539109544907

Nguyen, H. T. (2011). A longitudinal microanalysis of a second language learner's participation. In G. Pallotti \& J. Wagner (Eds.), L2 learning as social practice: Conversation-analytic perspectives (pp. 17-44). Honolulu, HI: University of Hawai'i at Manoa, National Foreign Language Resource Center.

Roebuck, R. F., \& Wagner, L. C. (2004). Teaching repetition as a communicative and cognitive tool: Evidence from a Spanish conversation class. International Journal of Applied Linguistics, 14(1), 70-89. https://doi.org/10.1111/j.1473-4192.2004.00054.x

Scollon, R., \& Scollon, S. W. (2001). Intercultural communication: A discourse approach. Chichester, UK: Wiley-Blackwell.

Seedhouse, P. (2004). The interactional architecture of the language classroom: A conversation analysis perspective. Malden, MA: Blackwell.

Sheen, R. (2002). 'Focus on form' and 'focus on forms.' ELT Journal, 56(3), 303-305. https://doi.org/10.1093/elt/56.3.303

Stivers, T. (2010). An overview of the question-response system in American English conversation. Journal of Pragmatics, 42(10), 2772-2781. https://doi.org/10.1016/j.pragma.2010.04.011

Storch, N., \& Wigglesworth, G. (2003). Is there a role for the use of the L1 in an L2 setting? TESOL Quarterly, 374), 760-770. https://doi.org/10.2307/3588224

Thompson, C., \& Millington, N. (2012). Task-based learning for communication and grammar use. Language Education in Asia, 3(2), 159-167. https://doi.org/10.5746/LEiA/12/V3/I2/A04/Thompson_Millington

Waring, H. Z. (2002). Displaying substantive recipiency in seminar discussion. Research on Language \& Social Interaction, 35(4), 453-479. https://doi.org/10.1207/S15327973RLSI3504_3 
Wong, J., \& Waring, H. Z. (2010). Conversation analysis and second language pedagogy: A guide for ESL/EFL teachers. New York, NY: Routledge.

Young, R. F. (2008). Interactional competence in language learning, teaching and testing. In E. Hinkel (Ed.), Handbook of research in second language teaching and learning (pp. 426441). London, UK: Routledge. 


\section{Appendix \\ Transcription Conventions \\ (Based on Filipi, 2007, and Jefferson, 2004)}

The transcription conventions are the following:

(0.0) Numbers in parentheses indicate elapsed time in silence by tenth of seconds within or between utterances, so (1.2) is a pause of 1 second and two-tenths of a second.

(.)

A dot in parentheses indicates a gap of less than two-tenths of a second within or between utterances.

$\rightarrow \quad$ An arrow indicates a point of interest which will be discussed in the analysis.

a::re $\quad$ The colon indicates lengthening of the preceding sound. Multiple colons indicate a more prolonged sound.

because Underlined type indicates marked stress.

SIMPLE: $\quad$ Upper case indicates increased volume.

${ }^{\circ}$ may be ${ }^{\circ} \quad$ Degree signs indicate the bracketed utterances are quieter in volume.

$<$ that is $>\quad$ The "less than" and "more than" symbols $<>$ indicate slower speech than the surrounding talk.

[ A single left bracket indicates the point of overlap onset.

\{ A curly left bracket indicates the incurring nonverbal onset.

((nods)) Double parentheses indicate a comment about actions noted in the transcript, including non-verbal actions.

$\uparrow \quad$ An upward arrow indicates raised pitch in the utterance part immediately following the arrow.

$\downarrow \quad$ A downward arrow indicates lowered pitch in the utterance part immediately following the arrow.

\$word\$ Dollar signs indicate a smiley voice. 